\title{
MOVEMENT OF PAIN SENSITIVE STRUCTURES IN THE VERTEBRAL CANAL IN A GROUP OF PHYSIOTHERAPY STUDENTS ${ }^{\dagger}$
}

\author{
G. D. MATTLAND*, A. U. A., F.C.S.P., F.A.C.P., M.A.P.A., M.S.A.S.P., M.T.A.A.
}

\section{SUMMARY}

A study was set up to relate the general degree of mobility of the pain sensitive siructures in the vertebral canal to the movement of the vertebral column. It was found that pain in area of the hamstrings or behind the knees on full extension of the knee, dorsiflexion of the foot and full flexion of the irunk, disappears when the neck flexion component is lost. It appears that hamstring or posterior knee pain and the concomitant decrease in range of movement are not caused by shortened hamstrings, but apparently by decreased movement of the structures between the sacrum and the skull. These structures are thus the pain sensitive structures within the vertebral canal.

Everyone who has been involved in the treatment of patients having pain arising from the vertebral column will have read about 'dural pain'. Most texts on manipulation will make reference to this dural pain and some authors make reference to the mechanism.

It is also believed that the dural sheath or nerve root sleeve can also be responsible for pain but the pain in these circumstances will be a referred pain.

It is common practice for medical practitioners and physiotherapists to measure the ranges of movement taking place at joints under examination while at the same time relating any pain which may be provoked by these movements. An evaluation is made as to whether the range and the pain provoked is normal or not, based upon a comparison with

the same movement in the joint on the opposite side of the body where possible;

the same movement in the joint above and the joint below, if the vertebral column is being examined;

that which is believed to be normal for that movement in that joint in a person with that body type under the existing conditions.

Although papers have been published giving details of the mean diameter of the vertebral canal at different levels of the spine, nowhere has it been published that the pain sensitive structures in the vertebral canal, such as the dura, the nerve root sleeve and the nerve root, may have a mean range of extensibility related to the movements of the spine. It was for this reason that the investigation reported on in this paper was undertaken. It seemed necessary to know what one could expect to be normal so as to have a measure from which to judge the abnormal.

* Senior Lecturer and Clinical Tutor for the Graduate Diploma of Advanced Manipulative Therapy, School of Physiotherapy, South Australian Institute of Technology.

t Read at the Inaugural Congress of the Manipulative Therapists Association of Australia, October 1978 and printed by kind permission of the Manipulative Therapists' Association of Australia.

Received 5 September 1979.

\section{OPSOMMING}

'n Studie is geloods om die algemene graad van lenigheid van die pyn sensitiewe strukture in die vertebrale kanaal in verwantskap met die bewegings van die werwelkolom te bring. Daar is gevind dat pyn wat in die area van die hampese of agter die kniee gevoel word wanneer volle ekstensie van die knie, dorsifleksie van die voet en volle rompfleksie gedoen word, verdwyn as die nek-fleksie-komponent verloor word. Dit blyk dm. hampees- of posterior kniepyn en die gelyktydige korting van omvang van beweging nie die gevolg van verkorte hampese is nie, maar blykbaar inkorting van beweging van die strukture tussen die sakrum en die skedel is. Hierdie strukture moet dus die pyn sensitiewe strukture binne die vertebrale kanaal wees.

There were two other factors which promted the initial thoughts regarding carrying out such an investigation. The first of these was that it seemed to the author that no one had suggested any physical examination procedure which satisfactorily tested the movements of these canal structures to such a degree that following examination the examiner would be able to say whether the movement of the pain sensitive structures in the vertebral canal and intervertebral foramen were normal or not. It is agreed that Lasègue's test and prone lying hip extension with knee flexion are tests for movements of the related nerve roots and presumably their nerve root sleeves. It has also been described that, with a patient lying supine and the examiner then passively flexing his head and neck so that his chin approximates his chest, test for dural involvement particularly in relation to low Jumbar pain. However, this test seems to be incomplete, especially when it is not uncommon to find that a patient with back pain will say that he has difficulty bending his head down while getting into a car because of back pain which this neck flexion produces, yet wa examination the supine lying neck flexion test is found to be negative. However, if, under these circumstances, the patient is asked to sit in a slumped position and to then put his chin onto his chest, it will be found that the range is limited by pain which is reproduced in his lower back. It therefore seemed necessary to develop a test which could adequately determine whether a patient's symptoms bore any relation to a limited range of movement within the vertebral canal and intervertebral foramen rather than due to movement of an intervertebral joint.

The second factor which initiated the thought of conducting a survey to determine the 'normals' was the publication of an article by Macnab (1971) in which he describes five sources of nerve root tension which include nerve root kinking by the pedicle, articular process impingement on the nerve root and spinal stenosis. Other authors including Fahrni (1966) make reference to nerve root adhesions simulating disc protrusion. The tests of straight leg raising, prone knee flexion and supine neck flexion were also inadequate in this instance to test fully the normal excursion of cephalad and caudad movement of the pain sensitive 
structures in the vertebral canal and intervertebral foramen. As a result of this inadequacy a test with the patient in a slump sitting position on an examination couch was insed to test these movements by variously adding and subtracting knee extension (simulating straight leg raising), ankle dorsiflexion, head and neck flexion and, if this total combined position could be adopted without restriction or pain, the trunk was further flexed on the femur (i.e. hip flexion) which it was hoped would place the canal structures on full stretch.

As these tests for canal movement were used in patients who had vertebral disorders, it was realised that it was necessary to have some idea of what the normal excursion should be in the normal average individual who has no pain. Therefore it was decided to undertake a survey on a group of normals, who, in this case, were physiotherapy students.

It was hoped also that the results of the survey would provide some further information in relation to e use of straight leg raising as a treatment technique, .Id, the concept of tight hamstrings. It is often suggested that when a patient feels pain in his hamstring area during straight leg raising, the technique is only stretching tight hamstrings. However, this does not seem to fit the clinical situations which are seen and which respond to straight leg raising as a trealnient procedure. Phalen and Dickson (1961), indicate very clearly a set of circumstances where some people may consider that patients have tight hamstrings. However, following corrective surgery for the spondylolisthesis the hamstring tightness disappeared, indicating that the apparent tightness of hamstrings had its origin in some fault of the lumbar spine rather than in the hamstrings themselves.

\section{METHOD}

Forty-nine physiotherapy students were examined to test what was presumed to be the range of movement of the pain sensitive structures in the vertebral canal. Of the forty-nine students examined, twenty-four have been excluded from this survey of normals'. Of the twenty-four who were excluded twenty-two were excluded because of back symptoms and two were excluded because of scoliosis. Twenty-five 'normals" remained of whom seven were male and eighteen were female. The average age of the males was 21 , varying from 20-23. The average age of the females was 20. lih an age span belween 19 and 24. No significant differences could be establıshed in the tests which could be attributed to the age. sex, body tipe or difference in height.

\section{Test Movements}

Forty-nine physiotherapy students were asked to fill in a questionnaire and the answers were verified, particularly in relation to any symptoms which may have been felt in the spine, particularly from the middle thoracic spine to the low lumbar spine. All forly-nine students were taken through the total examination routine. Each student was assessed during the test movements for pain (this included discomfort, stretching feelings, or any awareness of a different feeling provoked by the test movement) and the range of movement. The students were taken through the test routine described below, and will be referred to as being female.

\section{Standing:}

1.1 She was asked to report if she felt any discomfort. No one had any discomfort in standing.

1.2 She was asked to flex her trunk as far as possible and to remain in that position so that the range could be recorded. An assessment was simultaneously made of the contour of the spine. She was asked to report where she felt any pain or discomfort etc.

$1.3 \mathrm{In}$ this fully flexed position where the same degree of fiexion of the thoracic and lumbar spines and the hips was retained, she was asked to flex her chin onto her chest as far as possible and to repol't any changes in symptoms, or new symptoms. Over-pressure was also applied to the neck flexion by the examincr and the range of movement was assessed

1.4 On resuming the standing position she was asked if she considered that her range of flexion was her normal range, and whether it had changed in recent months.

The findings were recorded in Section A. Table I.

\section{Silling on examination couch.}

2.1 She was asked to sit well back until the posterior knee area was wedged against the edge of the examination couch so that uniformity of the test position would be maintained.

2.2 In this erect sitling position she was asked to report any pain or discomfort. None of the sludents reported any discomfort.

2.3 She was then asked to let her back slump through its full range of thoracic and lumbar flexion while al the same time not allowing her head and neck to drop into flexion. Once in this position firm overpressure was applied by the examiner to the shoulder area so as to fully stretch the thoracic and lumbar spines into fult flexion (Fig. 1). All the students were sympton? free.

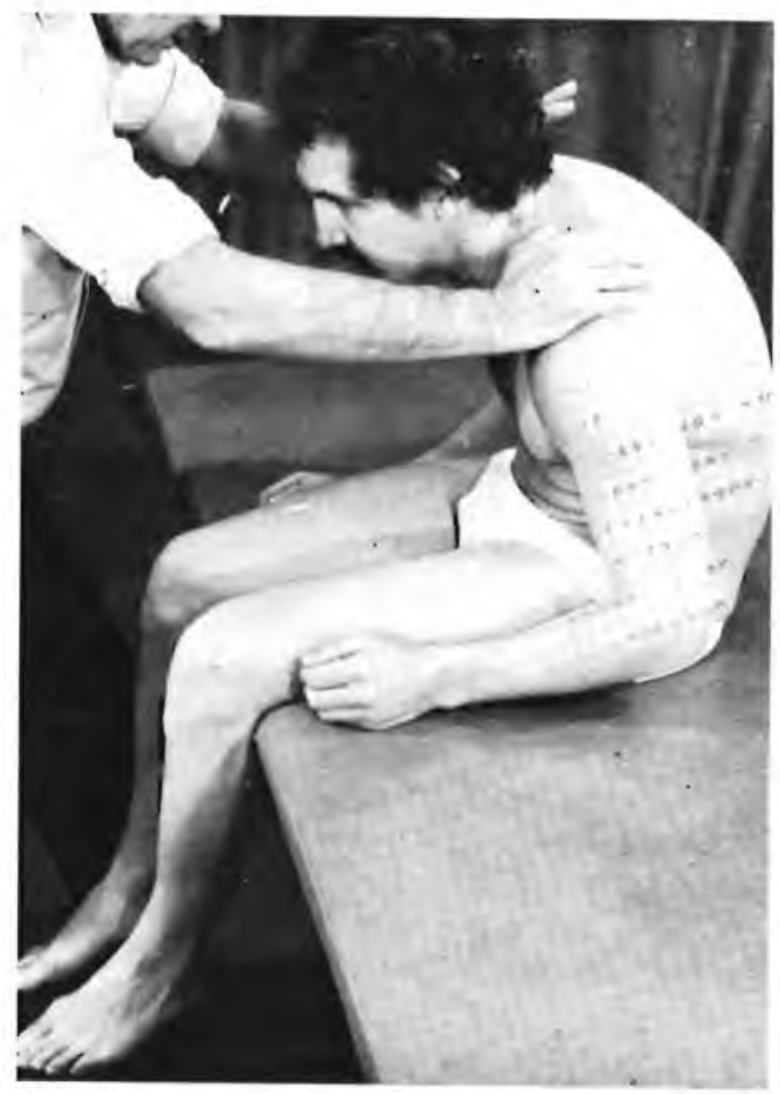

Fig. 1. 'Slump-sitting' with over-pressure 
TABLE I.

\section{CANAL MOVEMENTS}

NAME:

A STANDING FLEXION

Range

Pain

Is it usual range?

Has it changed recently?

Add NF O.P. $\left\{\begin{array}{l}\text { Range NF } \\ \text { Pain }\end{array}\right.$

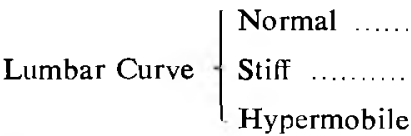

Thoracic Curve $\left\{\begin{array}{l}\text { Normal } \ldots \ldots \ldots \\ \text { Stiff } \ldots \ldots \ldots \ldots \\ \text { Hypermobile }\end{array}\right.$

B SITTING (T1 - Pelvis)

Sit, Pain

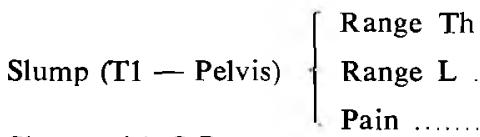

Slump with O.P.

1. Mid Position Pain

2. with hip F'd Pain

3. with hip E'd Pain

C NF COMPONENT

Slump (mid) + NF $\left\{\begin{array}{l}\text { Range } \\ \text { Pain }\end{array}\right.$

D SLR COMPONENT.

Slump (mid) 'NF-to-pelvis'

ADD SLR $\left\{\begin{array}{l}\text { Range } \ldots \ldots \ldots \ldots \ldots \ldots \ldots \ldots \ldots \ldots \ldots \ldots \ldots \ldots \ldots \ldots \ldots \ldots \ldots \ldots \ldots \ldots \ldots \ldots \ldots \ldots \ldots \ldots \ldots \ldots \\ \text { Pain } \ldots \ldots \ldots \ldots \ldots \ldots \ldots \ldots\end{array}\right\}$

(Don't allow Hip E)

\begin{tabular}{|c|c|c|}
\hline & Pain & Pain \\
\hline $\begin{array}{l}\text { F effect } \\
\text { lease NF }\end{array}$ & $\begin{array}{l}\text { New SLR Ran } \\
\text { New Pain }\end{array}$ & New SLR Range \\
\hline
\end{tabular}

E DF Component

Slump (mid) + NF + SLR (Lacks

${ }^{\circ}$ Kn.E. (HOLD) )

ADD DF $\left\{\begin{array}{l}\text { Range } \\ \text { Pain }\end{array}\right.$

$\left\{\begin{array}{l}\text { Range } \\ \text { Pain }\end{array}\right.$

1. NF Effect
(a) release NF
HOLD SLR
$\left\{\begin{array}{l}\text { Pain } \\ \text { New DF range } \\ \text { New pain }\end{array}\right.$
Pain
$\left\{\begin{array}{l}\text { Pain } \ldots \ldots \ldots \\ \text { New DF range } \\ \text { New pain }\end{array}\right.$
(b) NEW SLR
from NO DF
New DF range
New pain
Pain 


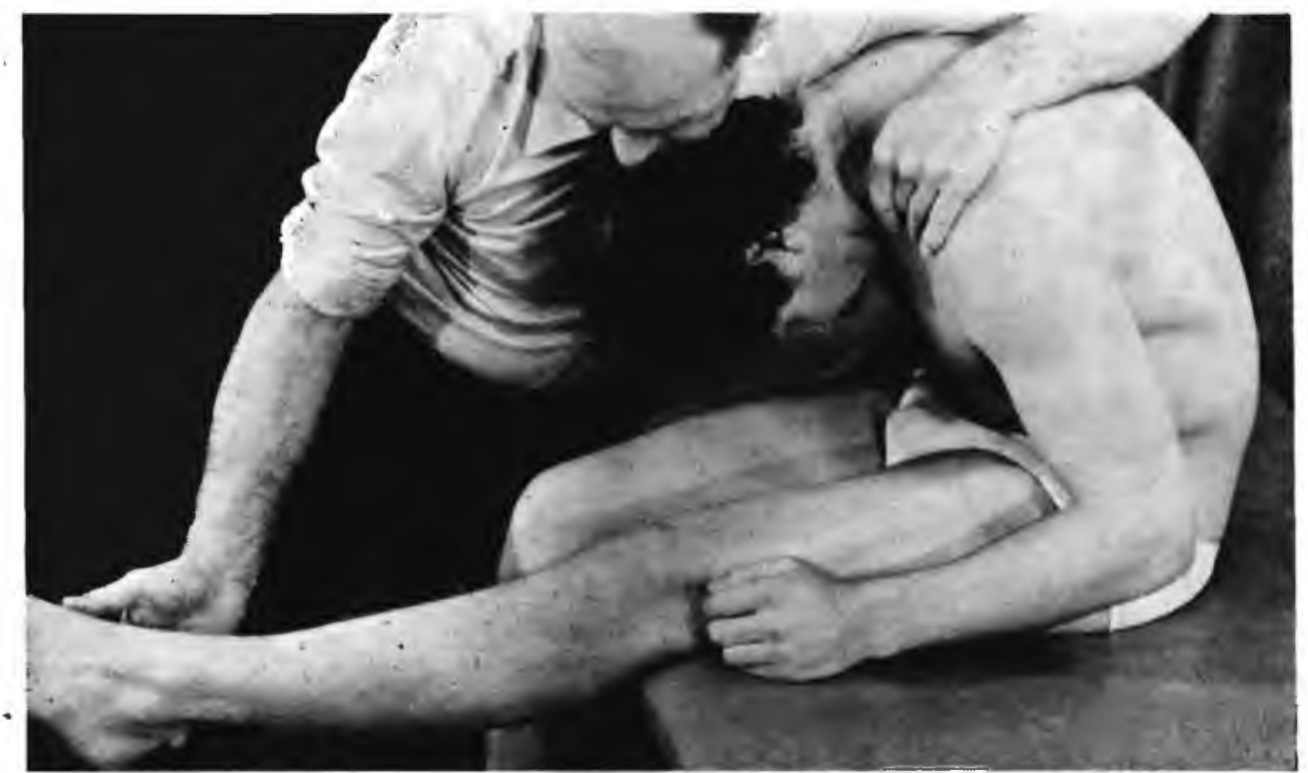

Fig. 4. 'Slump-sitting - real flexion' with superimposed knee extension (range of knee extension and pain response assessed).

In the fully slumped position the student may or may not have had a full-range of dorsiflexion.

2.9.3 When a student was unable to fully dorsiflex her ankle she was then asked, when the neck flexion was released, if she could dorsiflex her ankle further, and the new range and its pain response were reported and recorded in Section E, Table I. Not all the students were able to fully dorsifjex the ankle even at this stage.

2.10 When a student was unable to fully extend her knee two tests were carried out.

2.10.1 First she was asked to dorsiflex her ankle while her knee extension remained at the range available in the fully slumped position. The range and pain response was recorded in Section E, Table $I$.

2.10.2 Second, the neutral neck flexion position was retained and she was then asked to fully extend her knee. In this position she was then asked to attempt further dorsiflexion so that its new range and changes in pain could be recorded in Section E, Table $I$.

2.11 With the student sitting upright and with her knee fully extended, the normal full range of dorsiflexion and the pain response was assessed.

\section{RESULTS AND DISCUSSION}

\section{Standing (Table II)}

Of the seven males and eighteen females (total twenty-five) examined, only two (one male and one female) could be considered to be stiff. The remainder were at least able to touch their toes. The two students who were stiff also had a limitation of neck flexion

TABLE II.

Std. F. Std. F. + NF RANGE

$$
6
$$

NF $\vee$

$1 \mathrm{td}$

NF 1 td $\checkmark \quad$ NF $V$

17
Std. F. Pain

4 posterior knees

6

1 posterior knees + hamstring area

1 calf area

1 calf area

12 posterior knees

2 posterior knees \& hamstring area

I hamstring area only

1 calve

1 hamstring area \& calf area

1 posterior knce
Behaviour of Pain when NF superimposed

$2 \uparrow$

$2 \uparrow+$ buttock pain

$1 \uparrow$ both

I unchanged

$1 \uparrow$

$9 \uparrow$

$2 \uparrow+$ T10 pain

$1 \uparrow+$ centre low back area

$2 \uparrow$ both areas \& sprea hams higher

I $\uparrow$

$1 \uparrow$

$1 \uparrow$ both areas

$1 \uparrow$ 
when standing with the trunk fully flexed. Their pain responses will be seen to have no special significance when compared with those students having a normal range of movement.

When tested in standing the majority of students (twenty-one) felt pain behind their knees on touching their toes and it is interesting to note that by superimposing neck flexion on the trunk flexion this pain behind the knees increased in intensity. It is important to consider why this posterior knee pain should be increased in intensity when no extra strain or stretch is placed on the hamstrings or posterior knee soft tissue structures.

One male and two female students had pain both behind the knees and in the hamstring muscle area. Each had their pain increased by the superimposition of neck flexion. One female and two males had pain in the calf area, and of these three, the pain of two was increased by the superimposition of neck flexion while the pain of the third remained unchanged. One male and one female had pain in both the hamstring area and the calf area and both students had an increase in both areas of pain when neck flexion was superimposed.

Sitting, Slump Sitting, Superimposed Neck Flexion (Table III)

None of the twenty-five students had symptoms on sitting, either in the straight position or in the slumpsitting position (Figures 1 \& 2). Neither was there any restriction of range of neck flexion when this was superimposed on the slumped sitting position. However, the pain response on superimposing the neck flexion turned out to be interesting in that the findings were unexpected. The results are listed in Table III. Only five of the twenty-five students felt no discomfort whatsoever. Of the remaining twenty, seventeen felt symptoms centrally in the thoracic spine area at approximately T9. Sixteen felt the pain only in the centre of the T9 area whilst one also felt slight discomfort centrally in the lumbosacral area. The remaining three had atypical responses; one felt symptoms on the sides adjacent to the centre of the $T 9$ area, rather than centrally, another had symptoms in a similar distribution but extending down as far as the iliac crest, and the third felt symptoms in the right lower rib cage well laterally from the midline.

It would be interesting if the student who had central lumbosacral pain and the student who had right lower rib cage symptoms could be followed up over the next ten to twenty years to see whether they develop symptoms in these areas. If they were to develop symptoms in these areas it would then be interesting to note whether the 'superimposed neck flexion sign' became more positive, that is, whether the available range of neck flexion were lessened or the intensity of pain so provoked, were increased.
It seems from the above tests that provoking of symptoms in the T9 area can be classed as being within normal limits, and that, in fact, only a small percentage will have a painless full range in this position:

Slump Sitting plus Neck Flexion, Superimposing Knee Extension and Releasing Neck Flexion (Table IV)

The position shown in Figure 3 is adopted, where the examiner holds the student's head and neck in full flexion with his own chin, and his hands are free to encourage the student's knee extension and he is at the same time still able to observe the range of knee extension.

The student is now asked to extend her knee as far as possible and to report where symptoms are felt while the examiner assesses the range of knee extension (Figure 4). The range and pain response are shown in Table IV. While the examiner ensures that the student's knee remains in the same degree of extension, and also ensures that the thoracic and lumbar spine is held in the fully slumped position, the student is permitted to return the head and neck to the neutral position. The change in symptoms on releasing the neck flexion is recorded in the third part of Table IV. Also, if knee extension was limited when in the position shown in Figure 4 , once the neck flexion was released the student was asked to endeavour to extend the knee further and the resulting new range of knee extension and any discomfort provoked by this new range were listed in the third part of Table IV.

of the twenty-five students included in the survey, seventeen had a full range of knee extension with both left and right knees, two had a limitation of knee extension in the right knee whilst the left knee had full range, and the remaining five students had a degree of bilaterally equal limitation in each knee varying from three to thirty degrees, approximately.

Of the seventeen students who had full knee extension only three had no pain when each knee was extended. Of these three, two had no pain in slump sitting with full neck flexion and also had only slight pain behind their knees on standing with full trunk flexion which was only slightly increased when neck flexion was added. The third had very slight pain at the centre, T9 level and had calf pain on standing with full trunk flexion which increased when neck flexion was added. By reviewing the whole of Table IV it would seem that at one extreme of the range of normals, 3 students have pain free full slump sitting with neck flexion and knee extension superimposed. The biggest majority had their $T 9$ pain increased when adding knee extension. Also, with the addition of the knee extension, the majority had posterior knee pain provoked if they had this in the standing position. Others who had different areas of pain in the standing tests had these provoked once the knee was extended. Those who had calf pain in standing proved

TABLE III.

Slump-Sit

(Figs 1 \& 2)

$\mathrm{V}$

$\checkmark$

$\checkmark$

$\checkmark$

V

Range
$V$
$v$
$v$
$v$
$v$
$v$

Superimposed NF

Pain

$\checkmark$

\section{† T9 area}

sides of rather than $\dagger$

sides from T9 - iliac crest

$\mathbf{R}$ lower ribs laterally

+ T9 area plus slight central L/S pain

$\dagger=$ centre 
TABLE IV

FROM SLUMP-SIT + N.F. POSITION

Releasing NF

\begin{tabular}{|c|c|c|c|c|c|c|c|c|}
\hline \multirow{7}{*}{$\begin{array}{c}\text { Student } \\
\text { No. } \\
2 \\
5 \\
6 \\
8 \\
9\end{array}$} & \multirow{2}{*}{\multicolumn{3}{|c|}{$\begin{array}{l}\text { Pain felt in } \\
\text { standing test }\end{array}$}} & \multicolumn{2}{|r|}{ Adding Knee Ext } & \multirow{2}{*}{$\begin{array}{l}\text { Effect } \\
\text { on } \\
\text { pain }\end{array}$} & \multirow{2}{*}{$\begin{array}{l}\text { possible } \\
\text { to Knee } \\
\text { Ext. }\end{array}$} & \multirow{2}{*}{$\begin{array}{l}\text { Pain with new } \\
\text { Knee Ext. }\end{array}$} \\
\hline & & & & Range & Pain & & & \\
\hline & Post & Knee & & $\checkmark$ & v & & & \\
\hline & , & $\eta$ & & $\mathrm{v}$ & $\uparrow+$ Post $\mathbf{K n}$ & $v$ & & \\
\hline & $"$ & $"$ & & V & + Post $\mathbf{K n}_{\mathbf{n}}$ & $v$ & & nost $\mathrm{K}_{\mathrm{n}}$ \\
\hline & L " & " & & -20 & $\begin{array}{l}\uparrow \mathrm{T} 9+\text { Post Kn } \\
\text { T9 }\end{array}$ & $\begin{array}{l}V \\
V\end{array}$ & v & post Kn \\
\hline & $\mathbf{R} "$ & $"$ & & $-3^{\circ}$ & T9 $\uparrow+$ Post Kn & $\dot{v}$ & $\mathbf{R} \mathbf{V}$ & sl post $\mathbf{K n}$ \\
\hline $\begin{array}{l}10 \\
11\end{array}$ & 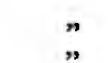 & $"$ & & $-5^{\circ}$ & $\begin{array}{l}\text { T9 } \uparrow+\text { Post Kn No L/S } \\
\text { T } 9 \uparrow+\text { Post Kn }\end{array}$ & $\begin{array}{l}v \\
v\end{array}$ & $\mathrm{~V}$ & sl post $\mathrm{Kn}$ \\
\hline 13 & & $"$ & & $\begin{array}{l}V \\
-30^{\circ}\end{array}$ & $V$ & & & \\
\hline $\begin{array}{l}14 \\
15\end{array}$ & $"$ & $"$ & & $-30^{\circ}$ & $\begin{array}{l}\text { T9 } \uparrow+\text { Post Kn } \\
\text { T9 ISQ no Post Kn }\end{array}$ & $\begin{array}{l}v \\
v\end{array}$ & v & s! post $\mathrm{Kn}$ \\
\hline 16 & $"$ & $"$ & & $v$ & $\mathrm{~T} 9 \uparrow+$ Butt to Post Kn & $v$ & & \\
\hline $\begin{array}{l}17 \\
18\end{array}$ & $"$ & $"$ & & $\begin{array}{l}v \\
V\end{array}$ & 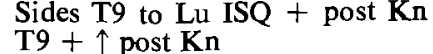 & $\frac{v}{v}$ & & \\
\hline 19 & $\begin{array}{l}\mathrm{L} \\
\mathrm{R}\end{array}$ & $"$ & & $\stackrel{v}{v}$ & $\begin{array}{l}\text { T9 ISQ + post Kn + L Butt } \\
,+ \text { R Butt }\end{array}$ & $\begin{array}{l}v \\
v\end{array}$ & & \\
\hline 21 & $"$ & $"$ & & $-5^{\circ}$ & T9 $\uparrow+$ Post Kn + low Butt & $\begin{array}{l}v \\
V\end{array}$ & $v$ & sl Hams + post Kn \\
\hline $\begin{array}{l}24 \\
12\end{array}$ & ${ }_{\mathrm{R}}^{\mathrm{L}}$ Post & K’nee & Hams & $\begin{array}{l}v \\
V \\
-10\end{array}$ & $\begin{array}{l}\text { No T9 post Kn } \\
\uparrow \text { T9 + Hams }\end{array}$ & $\begin{array}{l}y \\
y\end{array}$ & & \\
\hline $\begin{array}{r}1 \\
23 \\
3 \\
7\end{array}$ & $\begin{array}{l}\text { "” } \\
\text { Ham }\end{array}$ & $\begin{array}{l}" \prime \\
\text { ly" Calves }\end{array}$ & $"$ & $\begin{array}{l}-10 \\
-15^{\circ} \\
v \\
v\end{array}$ & $\begin{array}{l}\uparrow T 9+\text { R Butt } \\
\text { T9 + Post Kn }+ \text { Mid Hams } \\
\text { S1 T9 } \uparrow \text { Hams no Kn } \\
\text { T9 } 9+\text { Low Hams } \\
\text { T9 } 9+\text { Post Kn no Hams or } \\
\text { Calf }\end{array}$ & $\begin{array}{l}v \\
v \\
v \\
v \\
v\end{array}$ & V & $\begin{array}{l}\text { sl post kn } \\
\text { sl post kn }\end{array}$ \\
\hline $\begin{array}{r}20 \\
25 \\
4\end{array}$ & $\begin{array}{l}\text { Calve } \\
" \dddot{" 0}\end{array}$ & & & $-v^{3^{\circ}}-v^{2}$ & $\begin{array}{l}\text { No T9 sl Hams } \\
\text { No T9 (or Sit) post Kn } \\
\text { Sit T8 }\end{array}$ & $\begin{array}{l}v \\
v\end{array}$ & v & v sl Hams \\
\hline
\end{tabular}

to be an exception to this rule, but this only related to three students.

The most important to arise out of this part of the test.was that every student, when *neck flexion was released, completely lost all the symptoms which had previously been provoked. It would therefore seem that these symptoms were provoked by tension having been applied to the pain sensitive structures in the vertebral canal, because it is only these structures which are altered on releasing the neck flexion position. It is also important to note that those students who had a limitation of knee extension were able to have full range of knee extension once the neck flexion was released. In all the students but one, the only symptoms provoked by the improved range of knee extension was discomfort behind the knee.

\section{Superimposing Dorsiflexion of the Ankle}

When dorsiflexion is added to straight leg raising (Bragard's test) as an examination procedure for nerve root compression, it would seem reasonable to assume that it is only of value when the range of dorsiflexion is limited, coupled with reproduction of a patient's pain, provided this pain is not either in the calf or behind the knee. It is of interest to note the results of this survey of a selected group of so-called normals in relation to the range of dorsiflexion and the areas of pain so produced. Because of the complexity of trying to relate both range and pain with the other tests carried out on each student it is perhaps better to present different aspects of the findings rather than to describe the results for each student as is set out in the final (Table VIII).*

\section{Full Range Dorsiflexion (Table V)}

Only nine students had a full range of dorsiflexion and, with the exception of one student who had very slightly limited knee extension, they all had a full range of knee extension. There was only one student who had no pain with the full range of dorsiflexion. The remaining eight students had some pain with' dorsiffexion. It is important to note that with the release of neck flexion all pain caused by the dorsiflexion disappeared. This finding was valid for all the students.

\section{Symmetrical Limitation of Dorsiflexion (Table VI)}

Ten students had a limitation of dorsiflexion with full flexion of the spine and maximum knee extension. Of these ten, six had full range of knee extension, and the remaining four with limited dorsiflexion also had limitation of knee extension. For all ten students the limitation of dorsiflexion and extension where applicable, was the same for both left and right legs.

\section{Asymmetrical Limitation of Dorsiflexion (Table VII)}

The six remaining students had limited dorsiflexion which was different when comparing the left leg with the right. Three of these had full range of knee extension. Two of the other three had a matching

* Can be obtained from author at 175 Ward Street, Adelaide, South Australia 5600. 
TABLE $V$.

FULL RANGE OF DORSIFLEXION

\begin{tabular}{|c|c|c|c|c|c|c|c|}
\hline \multirow{4}{*}{$\begin{array}{c}\text { Student } \\
\text { No. } \\
2 \\
13\end{array}$} & \multicolumn{2}{|c|}{ Slump-sit $+\mathbf{N F}$} & \multicolumn{2}{|r|}{ Slump-sit + NF + Knee Ext. } & \multicolumn{2}{|c|}{ Adding Dorsiflexion } & \multirow{4}{*}{$\begin{array}{l}\text { Effect on } \\
\text { Releasing } \\
\text { NF }\end{array}$} \\
\hline & Range & Pain & Range & Pain & Range & Pain & \\
\hline & $v$ & v & $v$ & $v$ & $V$ & & \\
\hline & $\sqrt{ }$ & $V$ & V & v & $V$ & & \\
\hline 19 & $V$ & T9 & $V$ & T9 + ISQ Butt + Post Kn & $v$ & $\begin{array}{l}\text { post Kn } \\
\uparrow \text { Butt Kn } \\
\text { (T9 ISQ) }\end{array}$ & $\begin{array}{l}v \\
v\end{array}$ \\
\hline 4 & $V$ & T9 & $v$ & T9 ISQ & $v$ & $\uparrow \mathrm{T} 9$ & $v$ \\
\hline $\begin{array}{l}5 \\
6\end{array}$ & $\begin{array}{l}v \\
v\end{array}$ & $\begin{array}{l}\mathrm{T} 9 \\
\mathrm{R} \text { lat low } \\
\text { ribs }\end{array}$ & $\begin{array}{l}v \\
V\end{array}$ & $\begin{array}{l}\mathrm{T} 9 \uparrow+\text { post } \mathrm{Kn} \\
\text { ribs ISQ post } \mathrm{Kn}\end{array}$ & $\begin{array}{l}v \\
V\end{array}$ & $\begin{array}{l}\text { T9 ISQ post kn } \uparrow \\
\text { Ribs ISQ } \\
\text { post kn } \uparrow\end{array}$ & $\begin{array}{l}v \\
v\end{array}$ \\
\hline 7 & $\checkmark$ & T9 & $v$ & $\begin{array}{l}\mathrm{T} 9 \uparrow+\text { post } \mathrm{Kn} \text { (no hams, } \\
\text { calves) }\end{array}$ & $v$ & $\begin{array}{l}\text { sl } \uparrow \mathrm{T} 9+ \\
\text { calf, hams }\end{array}$ & $v$ \\
\hline 15 & V & T9 & v & T9 ISQ no Kn p & v & $\begin{array}{l}\text { T9 ISQ + } \\
\text { Post Kn }\end{array}$ & v \\
\hline 20 & $v$ & T9 & V. sl. ltd. & Hams & $v$ & T9 ISQ $\uparrow$ hams & V \\
\hline
\end{tabular}

TABLE VI. SYMMETRICAL LIMITATION OF DORSIFLEXION

$\begin{array}{cccl}\text { Student No. } & \begin{array}{c}\text { Range of } \\ \text { dorsiflexion }\end{array} & \begin{array}{c}\text { Range of } \\ \text { knee } \\ \text { extension }\end{array} & \text { Pain felt with the D.F. } \\ 3 & -25^{\circ} & \checkmark & \text { Hams } \\ 11 & -15^{\circ} & \checkmark & \text { post kn T9 hams } \\ 16 & -20^{\circ} & \checkmark & \text { T9 Butt. to post Kn. } \\ 17 & -10^{\circ} & \checkmark & \text { post kn. } \\ 18 & -20^{\circ} & \checkmark & \text { post kn. } \\ 24 & -10^{\circ} & -20^{\circ} & \text { post kn. } \\ 8 & -50^{\circ} & -30^{\circ} & \text { post kn. } \\ 14 & -30^{\circ} & -5^{\circ} & \text { post kn. } \\ 21 & -30^{\circ} & -15^{\circ} & \text { Hams, calves, post kns. } \\ 23 & -10^{\circ} & & \end{array}$

TABLE VII. ASYMMETRICAL LIMITATION OF DORSIFLEXION

\begin{tabular}{|c|c|c|c|}
\hline $\begin{array}{c}\text { Student No. } \\
1\end{array}$ & $\begin{array}{c}\text { Range of } \\
\text { dorsiflexion } \\
\text { L }-25^{\circ}\end{array}$ & $\begin{array}{c}\text { Range of } \\
\text { knee } \\
\text { extension } \\
\vee\end{array}$ & $\begin{array}{l}\text { Pain felt with the D.F. } \\
\text { Poist kn, Hams \& } T 9\end{array}$ \\
\hline 22 & $\begin{array}{l}R-10^{\circ} \\
L-5^{\circ} \\
R-2^{\circ}\end{array}$ & $\begin{array}{l}V \\
V \\
V\end{array}$ & T9, Butt \& Calves \\
\hline 25 & $\begin{array}{l}\mathrm{L}-30^{\circ} \\
\mathrm{R}-25^{\circ}\end{array}$ & v & L Calf \& L Butt. \\
\hline 9 & $\begin{array}{l}\mathrm{L}-25^{\circ} \\
\mathrm{R}-40^{\circ}\end{array}$ & $v-3^{\circ}$ & Post knees \\
\hline 12 & $\begin{array}{l}\mathrm{L}-15^{\circ} \\
\mathrm{R}-35^{\circ}\end{array}$ & $V-10^{\circ}$ & $\begin{array}{l}\text { L Hams } \\
\text { R Butt }++\end{array}$ \\
\hline 10 & $\begin{array}{l}\mathrm{L}-30^{\circ} \\
\mathrm{R}-20^{\circ}\end{array}$ & $\begin{array}{l}-5^{\circ} \\
-5^{\circ}\end{array}$ & Post knees and Hams \\
\hline
\end{tabular}

limitation to their range of knee extension whilst one had a bilaterally equal limitation of knee extension as compared with the asymmetrical limitation of the dorsiflexion.

\section{Pain Patterns}

The variation in patterns of pain produced by the various test movements was interesting to follow. In relation to the dorsiflexion movement the pain responses were as follows:

1. Increased pain in the $T 9$ area in six of the students. Twelve of the students who had T9 area pain while in the sitting neck flexion position, however, did not have this pain increased by the dorsiflexion despite the fact that the $\mathrm{T} 9$ pain was

increased with the knee extension movement.

2. Introduction or increased hamstring area pain or buttock pain in ten of the twenty-five students. If student No. 4 is included, because dorsiflexion increased pain in the T9 area, then eleven out of twenty-five students had pain provoked or introduced in areas other than in the calf or behind the knee.

It is useful to follow through the twelve unusual pain responses which occurred. Reference to Table VIII* will serve to clarify the following statements:

I. Student No. 4 had calf pain on standing with full trunk flexion. This pain was not reproduced at any other stage of the test.

* Can be obtained from author at 175 Ward Street, Adelaide, South Australia 5600. 
2. Student No. 6 had right lower rib pain felt laterally on sitting neck flexion. This pain was not provoked further by the remaining test movements.

3. Student No. 7 had hamstring and calf pain on standing ffexion, which was increased by neck flexion in standing. This was not affected by knee extension in sitting yet reproduced calf and hamstring pain with dorsiflexion.

4. Student No. 10 had lumbosacral pain when neck flexion was added to standing full trunk flexion. This pain was not reproduced in any other test position. This student did, however, have limitation of knee extension and dorsiflexion greater than nearly all of the other students.

5. Student No. 12 followed the common pattern with the initial tests until knee extension was introduced. At this point, the right movement showed restriction in range and marked increase of right buttock pain. It could prove interesting if this student were able to be followed over a period of twenty or thirty years to see if she develops back, right buttock or right sciatic pain for any reason.

6. Student 16 was one of two students to feel T9 area pain in flexion in standing when her neck was flexed. When knee extension was introduced into the test, not only did the T9 area pain increase but pain was also felt in the buttocks and hamstring area to behind the knees. This pain was further provoked by dorsiflexion which was limited. Follow-up in this case would be interesting.

7. Student No. 17 had a much wider distribution of pain during the sitting neck flexion test but as no other test movement was significant it is assumed that the wider area of pain is not significant.

8. Student No. 18 was the other student to present with pain in the T9 area standing trunk flexion plus neck flexion. There was nothing of further significance in her test movements.

9. Student 19 had buttock pain when neck flexion was added to the standing trunk flexion position. This pain was reproduced by both knee extension and dorsiflexion. Follow-up could again be of interest.

10. Student No. 20 had very limited trunk flexion in standing which provoked calf pain that increased with neck flexion. It is also of interest that the neck ffexion range was limited by this calf pain. Despite this examination finding none of the other test movements seemed to bear any relation to the findings on standing.

11. Student No. 22 had buttock pain reproduced in standing full flexion when neck flexion was added. This pain in the buttocks was further reproduced by knee extension and dorsiflexion. Again, a follow-up study could prove enlightening.

12. Student No. 25 had calf pain on standing full flexion which was reproduced by dorsiflexion in an asymmetrical manner. This is another example where follow-up could prove useful.

The comments in the above section have related basically to pain response. Comparisons regarding range of movement can be made by reference to columns 10 and 14 with columns 17,22 and 24 . Comparing colunms 10 and 17 it will be seen that they match much as one would anticipate, and when following this comparison through to column 22 in particular but also to column
24 where applicable, the figures do match in a predictable manner.

\section{SUMMARY}

Having tabulated the results of this survey of twentyfive supposed normals it is obvious that it can only be considered as a pilot study. The study needs to include a larger number of candidates. It should be expanded to test the normals in two other age groups, $11-13$ years and $35-45$ years. Possibly, if more scrupulous care were taken with the questioning of pain response to the test movements, some of the minor discrepancies in this survey might not have occurred. For example, the number of times when T9 area pain was not recorded as having been increased by the addition of knee extension. The normal test for straight leg raising should also be added to the test movements.

Furthermore, from this survey the following can be considered normal:

1. T9 area pain with trunk and neck flexion.
2. Pain behind the knees, and in some cases, in th. hamstring a rea.

3. Release of pain, provoked when knee extension and dorsiflexion are added to the neck and trunk flexion position, when flexion is released.

4. Full range knee extension with full trunk flexion in all but a very small percentage of examples.

5. Full range of dorsiflexion which was previously limited when neck flexion is released from its fully flexed position in the majority of examples.

6. Pain with some of the test movements in this slumped position. Only one of the twenty-five students had a full pain-free range.

The most significant finding from this survey is, however, the fact that pain felt in the area of the hamstrings or behind the knees when the knee is fully extended and the foot dorsiflexed while the trunk is fully flexed, disappears when the neck flexion component is released. Therefore, it seems logical to believe that the hamstring or posterior knee pain and its concurrent limitation of movement is due, not to 'tight hamstrings' but rather to the limitation of movement of structures between the sacrum and the skull. These structures must be the pain sensitive structures within the vertebral canal.

\section{Acknowledgements}

I would like to express my sincere thanks to Miss M. J. Hammond the Head of the School of Physiotherapy in South Australia, to Mrs M. Mernitz who organised the examinations of the students and also to thank the students themselves for being willing to take part in this survey. I would also like to express my thanks to Mr David Thompson, Mr Neil Merkel and Miss Margaret Simmonds for the visual aids which they have produced. Finally I must express my thanks to Mrs Helen Allen for struggling so successfully to reproduce the Tables, especially Table VIII.

\section{References}

Fahrni, W. H. (1966). Observations on straight leg raising with special reference to nerve root adhesions. Can. J. Surg. 9, 44.

Macnab, I. (1971). Negative disc exploration. An analysis of the causes of nerve root involvement in 68 patients. J. Bone \& $J$ t. Surg., 53A, 891.

Phalen, G. S. and Dickson, J. A. (1961): Spondylolisthesis and tight hamstrings, J. Bone \& Jt. Surg., 43A, 505. 